\title{
El Golem
}

\author{
María Kodama \\ Fundación Internacional Jorge Luis Borges
}

El Golem es la novela más conocida de Meyrimk, el escritor vienés que vivió muchos años en Praga, la ciudad donde situó su novela fantástica publicada en 1915. ¿Cuándo la habrá leído Borges? No encontré la fecha. Quizás antes de irse a Ginebra, en 1914. Antes ya había aprendido el alemán.

En el breve prefacio que hizo muchos años después sólo para este libro, que integra la Biblioteca Personal de la Colección Hispamérica dice de Meyrimk: «Antes de ser un buen terrorista de la literatura fantástica, Meyrimk fue buen poeta satírico» (1985). Juicio en que se nota algo de humor que podría darse entre los dos escritores, como un juego travieso del que es cómplice y participante, también, el lector,

Al leer El Golem de Meyrimk comprendemos la fascinación que sintió Borges, no sólo como lectura, sino por la influencia que ejerció en él. Esto no puede asombrar porque toda la duda metafísica está demostrada en esa obra.

La novela comienza como un sueño. Hasta el final no se sabe cuál es la realidad y cuál es la fantasía. El narrador siente la fascinación de su cuerpo, su yo se disuelve, se aleja, ya no está.

Al despertar se encuentra en una miserable casa del ghetto, confusamente le llegan recuerdos del sueño, quizás recuerdos de algo leído. Van apareciendo diversos personajes: un cambalachero, Haron Wassertrum con su hija Rosina, dos gemelos abandonados a los que ella cuida y que mendigan para ellos, un marionetista, Zwakh. Al narrador, un restaurador de antigüedades, lo llaman maestro Pernath. El narrador no sabe si ese nombre es el suyo, se mezcla la realidad y el sueño. Cree que hace tiempo se puso confundido otro sombrero y que ese sombrero tenía una cinta en el interior que decía "Athanasius Pernath».

Luego un hombre lo sigue por la escalera, y lleva un libro titulado Ibbur, la saturación del alma, cuando lo lee siente que «todo lo que me había dicho la voz lo había llevado toda mi vida dentro de mí, solo que había estado oculto y olvidado y se había mantenido escondido en mis pensamientos hasta hoy». Ya solo en su cuarto ve que su cara no era la suya y se dice a sí mismo: «Soy yo. Yo, yo, Athanasius Pernath». Hay aquí un sentimiento análogo al de Borges cuando Borges considera

- María Kodama nació en Buenos Aires. Es escritora, traductora y se recibió en la Facultad de Filosofía y Letras de Profesora en Literatura. Preside la Fundación Internacional Jorge Luis Borges, que creó en 1988. Su aporte a la difusión del universo borgeano ha sido reconocido con innumerables distinciones. 
la interacción entre el lector y la obra que tendrá cambios sucesivos según se lea en distintos momentos de su vida y por supuesto, se multiplicarán estos cambios con la interrelación de cada lector con la obra, a través de los siglos.

La idea del desconocido que entrega algo que puede cambiar el destino del que lo recibe está presente en «El Zahir» o en "La memoria de Shakespeare». Así como otro de los temas recurrentes es el tema del doble, por otra parte tan presente en la literatura universal desde el mito de Narciso, pasando por autores como Stevenson o Wilde y culminando con Borges.

Luego, se reúnen con Pernath el marionetista Zwakh, el músico Josua Prokob y el pintor Vrieslander que está tallando una cabeza en madera. Introducen a Pernath en un mundo de magia y alegría, de música y de antiguas leyendas. Hablan del Golem. Según el marionetista, cada treinta y tres años aparece en el ghetto un hombre por las calles que, de repente, se hace invisible. Hace años se lo vio partir de una casa antiquísima cerca de la sinagoga, en un trayecto circular, que lo devuelve a ella. Ese edificio de la Antigua Escuela tiene una habitación sin ningún acceso, con una ventana con rejas. Alguien bajó atado a una cuerda para ver su interior, se rompió la cuerda y murió en su caída.

Piensa el marionetista que quizás surge en el barrio judío esa aparición, en cada generación, de modo que, como en un espejismo, ven los rasgos de un ser característico: tal vez vive aquí desde hace siglos y ansía corporizarse. Tal vez no lo percibimos y está siempre en nosotros.

El escultor termina de tallar la cabeza. El narrador reconoce la cara del que le llevó a restaurar el libro Ibbur. Luego ve que se había convertido en él mismo. El marionetista grita que era el Golem, Vrieslander el escultor niega el parecido y tira la cabeza a la calle. El narrador pierde el sentido. Al reaccionar lo invitan a divertirse en el Salón Loisitschek. La música, los cuentos, las parejas bailando, el horror de lo inesperado, todo se mezcla en su cabeza.

Ya en su casa despierta de su desmayo, lo cuida el archivero Hillel quien, a través del tiempo, lo introduce en el mundo espiritual, le explica que, aunque lo ha olvidado, él ha elegido el camino de la vida dentro del tiempo, no la muerte y le asegura que con el conocimiento le llegará también el recuerdo. (Quizás haya aquí una finísima sátira al psicoanálisis de Freud, otro austríaco).

Por ese camino, le aguardarán al narrador terribles experiencias y el deslumbramiento de encuentros inesperados. Vuelve a ver a Angelina, a quien ayudó cuando nińa y que le ruega que la auxilie ahora. También se preocupa por Miriam, la hija del archivero. Ella ha rogado por un milagro que alivie la pobreza en que viven su padre y ella. Pernath le hace llegar el dinero de modo tal que parezca un milagro. Enamorado de Angelina, piensa que Miriam, hija del maestro espiritual, es la mujer ideal. La muchacha le confiesa uno de sus sueños, es el de dos seres que se funden el uno en el otro como un solo ser, quizás como el «hermafrodita» del antiguo culto de Osiris. Lo masculino y lo femenino en la figura humana del semidiós.

Pernath correrá una serie de peligros, de los que no sale indemne y, pese a su total inocencia, terminará pasando años en la cárcel, siempre confiando en que el camino de la verdad y de la justicia procurará su libertad. Lo logra al fin, gracias a la amistad y al destino.

Ya libre, piensa que en las antiguas calles del barrio judío encontrará a sus amigos, pero cuando llega al ghetto, han desaparecido los lugares tan andados, han levantado el pavimento por todas partes para instalar las redes de sanidad en todo el barrio. 
Tampoco halla a ninguno de aquellos amigos que lo acompañaron. Solo encuentra en un café a Jaromin, el mellizo sordomudo que acompañaba a Rosina. Trata de pedirle noticias de todos, pero sólo le contesta con señas que Pernath no puede entender.

Había alquilado dos buhardillas en la calle de la Vieja Escuela, la casa era la misma donde, según la leyenda, había desaparecido el Golem.

Era nochebuena, tenía un pequeño abeto, también había prendido velas. Solo lo acompañaban sus recuerdos. De repente, se halló entre las llamas de la habitación incendiada. Logró atarse una soga y salir por la ventana. En su descenso, al pasar por la ventana enrejada vio a través de los cristales a Hillel y a Miriam, gritó, quiso detenerse, soltó la soga y cayó como una figura de una carta del taroth «con la cabeza hacia abajo y las piernas cruzadas, entre el cielo y la tierra».

Está en su hotel, se levanta, trata de recordar, solo ha dormido una hora, soñó, pero no puede haber sido un sueńo. No se llama Pernath. Allí está colgado el sombrero que hoy tomó al confundirse, sentado en un banco, durante la misa mayor, en la Catedral de Hadschrim. En el forro de la seda hay un nombre: Athanasius Pernath. Sale, ordena un coche que lo lleva al barrio judío. A la taberna Zum Loisitschek. Lleva el sombrero envuelto, casi nuevo y quebradizo como si fuera antiquísimo.

Vivió la existencia de Pernath en un sueño, pero ¿por qué no sabe lo que vio él a través de la ventana cuando gritó ¡Hillel!?

Comprende ahora, en ese momento se separó él del narrador, de su doble. Debe encontrar a ese Pernath.

El café Loisitschek no es ya el mismo, pero en algo se parece al del sueño. Dice ser escritor y quiere que le hablen del antiguo barrio judío. Juega al billar con un apuntador al que recuerda como un hombre con fortuna. Ahora, sin rastros de ella, juega por dinero. El narrador le pregunta por Pernath, el apuntador le mira fijamente y le pregunta si es un pariente. Niega esto. Lo único que el apuntador cree recordar es que Pernath se casó con una bella judía morena. ¡Miriam!, se dice el narrador, que tanto la ha buscado. Un barquero dice conocer dónde vive Pernath y será el que lo lleve en su barca hasta la casa de Miriam. En el trayecto hasta el Moldava para tomar a barca, pasan por la casa incendiada, pero no hay huellas de las llamas. Pregunta cuándo se incendió la casa y le contesta que nunca ha ocurrido tal cosa.

Cuando llega a la calle de los alquimistas, a la casa blanca, un castillo donde vio una vez a Angelina, casa de leyenda, donde se dice que nadie puede entrar, ni siquiera verla si no se trata de un elegido, ve que la puerta tallada es el Dios Osiris. Un jardinero se acerca y el narrador le entrega el sombrero envuelto de Athanasius Pernath. Hay un jardín maravilloso allí. Cuando la puerta se abre nuevamente, ve una casa de mármol, como un templo y en sus escaleras, mirándolo, están Athanasius Pernath, su doble y Miriam apoyada en él, sonriéndole al narrador, que se siente como ante un espejo.

La puerta se cierra. El criado le entrega su sombrero y le transmite el agradecimiento de Pernath por llevárselo y también sus disculpas: por una antigua norma de la casa no puede invitarlo al jardín. También le hace saber que él no se ha puesto el sombrero, porque enseguida descubrió el cambio. Sólo espera que el suyo no le haya causado muchos dolores de cabeza.

Quizás, como en la novela de Meyrimk, la existencia sea un camino regido por el azar. Un cambio de sombrero será, tal vez, la única diferencia entre el bien y el mal, entre la dicha y la desdicha, entre el narrador y su doble. Un juego entre la 
realidad y el sueño, entre la existencia y la muerte. ¿Cuál de ellos es el verdadero hombre? ¿el narrador o su doble? ¿es que hay un hombre verdadero? ¿o todos son roles que dependen de quien sueña y de quién es soñado?

El relator no tiene nombre, quizás nunca lo tenga, salvo en los momentos en que lleve un sombrero ajeno en su cabeza. Quizás sea el Golem paseándose entre la gente aterrorizada, con el terror de la razón que pretende transitar por calles tranquilas o fáciles de ubicar con una guía segura.

De todos modos, al final, antes de llegar a ver de lejos, el jardín que le está vedado, el relator ya no se presenta como Pernath ni es, tampoco, restaurador de antigüedades. En el café ha dicho ser escritor. Sí, ¿por qué no creerle nosotros, los lectores, aunque haya dicho una mentira para conseguir información? Como escritor se ha metido en el viejo barrio judío y en la piel de esos seres que pueblan o poblaron el barrio, en sus templos y sus religiones, en sus pasiones y temores, en la vieja Praga tan recorrida por Meyrimk durante años.

Todo eso deja cuando devuelve el sombrero a Pernath, su doble que nunca mentía. Libre ya, el escritor, con su propia cabeza lista para pensar otra historia.

Y así Borges, lector adolescente de El Golem se convirtió, pasado el tiempo —esa red que a todo ser viviente aprisiona — en el autor de «El Golem» (1989:163), el poema que en varias ocasiones consideró el mejor de los suyos.

En Conversaciones con Jorge Luis Borges (1970) de Richard Burgin, Borges explica que el poema sigue el desarrollo de la evolución del Golem y que luego hay una parábola, porque habíamos pensado que el Golem era un ser torpe y desmañado, del cual el rabino estaba avergonzado y, al final, se sugiere que el Golem representa para el mago lo mismo que el hombre para Dios y que, quizás, Dios podría también sentirse avergonzado de la humanidad como el cabalista lo estaba del Golem. Además, podría encontrarse en este poema una parábola del arte: aunque el rabino había emprendido algo hermoso y muy importante: la creación de un hombre, solo había conseguido un muñeco torpe y deforme, algo como una parodia de la humanidad. Borges termina afirmando que le gustan los últimos versos y que ése es su mejor poema.

Entre la leyenda de Meyrimk que cita Borges y su poema, hay muchas diferencias. Leamos algunas estrofas:

Sediento de saber lo que Dios sabe,

Judá León se dio a permutaciones

de letras y a complejas variaciones.

$\mathrm{Y}$ al fin pronunció el Nombre que es la Clave

la Puerta, el Eco, el Huésped y el Palacio,

sobre un muñeco que con torpes manos

labró, para enseńarle los arcanos

de las letras, del tiempo y del espacio.

Tal vez hubo un error en la grafía

o en la articulación del sacro nombre.

A pesar de tan alta hechicería,

no aprendió a hablar el aprendiz de hombre.

Elevando a su Dios manos filiales,

las devociones de su Dios copiaba

o, estúpido y sonriente, se ahuecaba 
en cóncavas zalemas orientales.

El rabí lo miraba con ternura

y con algún horror. ¿Cómo (se dijo)

pude engendrar este penoso hijo

y la inacción dejé, que es la cordura?

¿Por qué di en agregar a la infinita

serie un símbolo más? ¿Por qué a la vana

madeja que en lo eterno se devana,

di otra causa, otro afecto y otra cuita?

En la hora de angustia y de luz vaga,

en su Golem los ojos detenía.

¿Quién nos dirá las cosas que sentía

Dios, al mirar a su rabino en Praga?

En la leyenda, el Golem es construido por el rabino con un fin utilitario, para un trabajo determinado, como un autómata al que se diera cuerda. No hay afecto hacia su creación. En el poema, por el contrario, ese ser torpe que copiaba los gestos y ademanes de la oración de su creador, su Dios, le inspiraba ternura. Dios le inspiraba ternura y desesperación el mago, que asumía su propia incapacidad y su responsabilidad por ese ser que había creado.

«El Golem» se publicó por primera vez en la revista Davar en el año 1958; pero antes, en 1940, en la revista Sur, Borges presentó su bellísimo cuento "Las ruinas circulares».

No recuerdo en qué entrevista Borges contaba que una lectora, en los Estados Unidos, le había señalado el parecido entre su cuento «Las ruinas circulares» y su poema «El Golem». Él dijo que no había notado el parecido pero que creía que era una mágica coincidencia que se lo hiciera ver en un viaje tan maravilloso como el que estaba haciendo.

La cortesía es una gran virtud. Naturalmente, si se conocen las dos obras, la una hace pensar enseguida en la otra. Y con todo, qué diferentes son las dos, y qué maestría la del escritor argentino para lograr dos ambientes, dos épocas completamente distintas con un mismo tema. En el poema, aunque hay estrofas de un malicioso humor, consigue un acento austero, de una época que ya cuestiona todo el pasado, pero viéndolo como un cuadro valioso por lo bello y como único testigo de la larga cadena de hechos y creencias que vivieron los hombres.

El cuento «Las ruinas circulares» nos presenta a un hombre que llega a un templo destruido, alejado de las poblaciones, para conseguir la paz que le demanda su deseo de soñar un hombre. Todos conocemos el argumento. Pasa noches sin conseguir lo que quiere. Por fin pudo soñar un hombre íntegro, pero estaba inmóvil, sin ninguna señal de vida. Entonces le rogó a la rara esfinge del templo, de las ruinas del tempo mejor dicho, que lo ayudara. La esfinge le dijo que su nombre en la tierra era Fuego y que lo ayudaría a animar al ser sońado, siempre que sólo Fuego y el hombre supieran que su creación no era un hombre de carne y hueso. Todos los demás lo creerían tal. Una vez que lo instruyera en los ritos debía mandarlo a otro templo destruido, para que enseñara a los hombres a reverenciar al Dios Fuego. Entonces, en el sueño del soñador, el sońado despertó. Una vez que lo instruyó en los rituales, lo envió lejos, como había prometido.

Una noche lo despertaron unos remeros quienes le contaron que en el templo del Norte había un hombre capaz de pisar el fuego sin quemarse. Tuvo miedo 
por la humillación que su hijo sufriría al saber que era sólo un fantasma, sólo la proyección del sueño de otro hombre. Y el título lo dice: se repite el círculo, un día se quemó lo que quedaba de su templo, decidió no buscar salvación, moriría en el fuego y, luego «con alivio, con humillación, con terror comprendió que él también era una apariencia, que otro estaba soñándolo».

La diferencia es notable: este hombre, este ser que se cree a sí mismo un hombre, creado en las ruinas de un templo por un hombre, es puramente inmaterial, un sueño, un sueño que dura lo que su aparente vida, quizás, porque su padre se comunica con él a distancia, todas las noches en sus sueños.

Y nuestra duda permanente, la que nos llega en el mensaje de las palabras leídas: quizás nada sea real, todo es sueños que siguen a otros sueños y el amor, al ser creado por un idealista, y el orgullo y el dolor por la humillación sufrida y la libertad del ser humano que insiste en golpear a las puertas de lo desconocido sin hallar respuesta, y Meyrimk, con su narrador que no tiene nombre, como tampoco lo tiene el hombre que vivió un sueño dentro de otro sueño en «Las ruinas circulares».

\section{Referencias bibliográficas}

Burguin, R. (1970). Conversations with Jorge Luis Borges. Avon Books. (Resumen en traducción libre).

Borges, J.L. (1989). El Golem. En «El otro, el mismo». Obras Completas. T.2. Emecé.

Borges, J.L. (1958). El Golem. Davar (77), 3-5.

Borges, J.L. (1940). Las ruinas circulares. Revista Sur (75), 100-106.

Meyrimк, G. (1985). El Golem. En Colección de la Biblioteca Personal (dirigida por J.J. Borges en colaboración con María Kodama). Hispamérica ed. Argentina. 